\title{
Fluconazole-Resistant Candida glabrata Bloodstream Isolates, South Korea, 2008-2018
}

Eun Jeong Won, ${ }^{1}$ Min Ji Choi, ${ }^{1}$ Mi-Na Kim, Dongeun Yong, Wee Gyo Lee, Young Uh, Taek Soo Kim, Seung Ah Byeon, Seung Yeob Lee, Soo Hyun Kim, Jong Hee Shin

\begin{abstract}
Medscape ACTIVITY
In support of improving patient care, this activity has been planned and implemented by Medscape, LLC and Emerging Infectious Diseases. Medscape, LLC is jointly accredited by the Accreditation Council for Continuing Medical Education (ACCME), the Accreditation Council for Pharmacy Education (ACPE), and the American Nurses Credentialing Center (ANCC), to provide continuing education for the healthcare team.

Medscape, LLC designates this Journal-based CME activity for a maximum of 1.00 AMA PRA Category 1 Credit(s) ${ }^{\mathrm{TM}}$. Physicians should claim only the credit commensurate with the extent of their participation in the activity.

Successful completion of this CME activity, which includes participation in the evaluation component, enables the participant to earn up to $1.0 \mathrm{MOC}$ points in the American Board of Internal Medicine's (ABIM) Maintenance of Certification (MOC) program. Participants will earn MOC points equivalent to the amount of CME credits claimed for the activity. It is the CME activity provider's responsibility to submit participant completion information to ACCME for the purpose of granting ABIM MOC credit.

All other clinicians completing this activity will be issued a certificate of participation. To participate in this journal CME activity: (1) review the learning objectives and author disclosures; (2) study the education content; (3) take the post-test with a $75 \%$ minimum passing score and complete the evaluation at http://www.medscape.org/journal/eid; and (4) view/print certificate. For CME questions, see page XXX.
\end{abstract}

Release date: February 17, 2021; Expiration date: February 17, 2022

Learning Objectives

Upon completion of this activity, participants will be able to:

- Assess the mortality and antifungal resistance (including fluconazole resistance) of C. glabrata bloodstream isolates, based on a study of South Korean

multicenter surveillance cultures collected during an 11-year period (2008-2018)

- Evaluate antifungal resistance molecular mechanisms, including amino acid substitutions of fluconazole-resistant $C$. glabrata bloodstream

isolates, based on a study of South Korean multicenter surveillance cultures collected during an 11-year period (20082018)

- Determine the clinical and public health implications of outcomes and antifungal-resistant molecular mechanisms of fluconazole-resistant $C$.

glabrata bloodstream isolates, based on a study of South Korean multicenter surveillance cultures collected during an 11year period (2008-2018)

\section{CME Editor}

Jude Rutledge, BA, Technical Writer/Editor, Emerging Infectious Diseases. Disclosure: Jude Rutledge has disclosed no relevant financial relationships.

\section{CME Author}

Laurie Barclay, MD, freelance writer and reviewer, Medscape, LLC. Disclosure: Laurie Barclay, MD, has disclosed no relevant financial relationships.

\section{Authors}

Disclosures: Eun Jeong Won, MD, PhD; Min Ji Choi, PhD; Mi-Na Kim, MD, PhD; Dongeun Yong, MD, PhD; Wee Gyo Lee, MD, PhD; Young Uh, MD, PhD; Taek Soo Kim, MD; Seung Ah Byeon, MS; Seung Yeob Lee, MD, PhD; Soo Hyun Kim, MD, PhD; and Jong Hee Shin, MD, PhD, have disclosed no relevant financial relationships.

Author affiliations: Chonnam National University Medical School,

Gwangju, South Korea (E.J. Won, M.J. Choi, S.A. Byeon, S.Y.

Lee, S.H. Kim, J.H. Shin); Asan Medical Center, University of

Ulsan College of Medicine, Seoul, South Korea (M.-N. Kim);

Yonsei University College of Medicine, Seoul (D. Yong);

Ajou University School of Medicine, Suwon, South Korea
(W.G. Lee); Yonsei University Wonju College of Medicine, Wonju, South Korea (Y. Uh); Seoul National University College of Medicine, Seoul (T.S. Kim)

DOI: https://doi.org/10.3201/eid2703.203482

${ }^{1}$ These first authors contributed equally to this article. 
We investigated the clinical outcomes and molecular mechanisms of fluconazole-resistant (FR) Candida glabrata bloodstream infections. Among 1,158 isolates collected during multicenter studies in South Korea during 2008-2018, 5.7\% were FR. For 64 patients with FR bloodstream infection isolates, the 30 -day mortality rate was $60.9 \%$ and the 90 -day mortality rate $78.2 \%$; these rates were significantly higher than in patients with fluconazole-susceptible dose-dependent isolates (30-day mortality rate $36.4 \%$, 90-day mortality rate $43.8 \%$; $p<0.05$ ). For patients with FR isolates, appropriate antifungal therapy was the only independent protective factor associated with 30-day (hazard ratio 0.304) and 90-day (hazard ratio 0.310 ) mortality. Sequencing of pleiotropic drug-resistance transcription factor revealed that 1-2 additional Pdr1p amino acid substitutions (except genotype-specific Pdr1p amino acid substitutions) occurred in $98.5 \%$ of FR isolates but in only $0.9 \%$ of fluconazole-susceptible dose-dependent isolates. These results highlight the high mortality rate of patients infected with FR C. glabrata BSI isolates harboring Pdr1p mutations.

\section{C} andida glabrata is a commensal yeast in the human gut, genitourinary tract, or oral cavity; however, it can cause serious bloodstream infections (BSIs) that result in substantial illness and death (1). Unlike other common Candida species, C. glabrata exhibits intrinsically low susceptibility to azole drugs, especially fluconazole, and rapidly acquires antifungal resistance in response to azole or echinocandin exposure (1-3). Although the incidence of echinocandin- and multidrug-resistant (MDR) C. glabrata BSIs is low, fluconazole resistant (FR) C. glabrata BSI isolates have been increasingly reported worldwide, typically at rates of $2.6 \%-10.6 \%$, although these rates can reach $17 \%(4-6)$. Fluconazole resistance in C. glabrata is of particular concern because of the increased incidence of BSIs caused by this species in various locations worldwide $(1,4,5)$. Acquired azole resistance in C. glabrata is most commonly mediated by overexpression of the drug-efflux transporter genes $C g C D R 1, C g C D R 2$, and CgSNQ2 through a gain-of-function (GOF) mutation in the transcription factor pleiotropic drug-resistance (PDR1) $(2,7,8)$, although other mechanisms might contribute (9-11).

PDR1 mutations in C. glabrata associated with azole resistance have been shown to cause hypervirulence in a mouse model of systemic candidiasis, suggesting the need for careful monitoring of FR C. glabrata BSI isolates and their PDR1 mutations $(7,12)$. To date, little substantial research has been conducted on PDR1 mutation incidence among FR C. glabrata BSI isolates from multicenter surveillance cultures or on mortality rates of patients infected with these
PDR1 mutants. This deficit might be attributable to Pdr1p amino acid substitutions (AAS) found in FR and fluconazole-susceptible dose-dependent (F-SDD) isolates $(7,13,14)$, which can impede determination of whether specific Pdr1p AAS result in fluconazole resistance. Therefore, the aim of this study was to investigate the clinical outcomes, molecular mechanisms, and genotypes associated with antifungal-resistant BSI isolates of $C$. glabrata collected during multicenter studies in South Korea during an 11-year period (2008-2018). We focused on the mortality rates of patients infected with FR C. glabrata BSI isolates harboring the Pdr1p mutation.

\section{Materials and Methods}

\section{Microorganisms and Antifungal Susceptibility Testing}

A total of 1,158 BSI isolates of $C$. glabrata were collected from 19 university hospitals in South Korea during January 2008-December 2018 (Appendix Table 1, https://wwwnc.cdc.gov/EID/article/27/3/203482-App1.pdf). All isolates were collected from routine blood cultures by using methods that varied among laboratories; only the first isolate from each patient was included. The hospitals participating in this laboratory-based nationwide multicenter surveillance system differed each year. All C. glabrata isolates were submitted to Chonnam National University Hospital (Gwangju, South Korea) for testing. Species identification was based on matrix-assisted laser desorption/ionization time-of-flight mass spectrometry (Biotyper; Bruker Daltonics, https:/ /www. bruker.com) with library version 4.0 , or sequencing of the D1/D2 domains of the 26S rRNA gene, to differentiate C. glabrata from cryptic species (C. nivariensis and C. bracarensis) within the C. glabrata complex (15). In vitro testing of susceptibility to fluconazole, micafungin, caspofungin, voriconazole, and amphotericin B was performed for all isolates according to the Clinical and Laboratory Standards Institute broth microdilution method (16). MICs were determined after 24 hours of incubation. Two reference strains, Candida parapsilosis ATCC 22019 and Candida krusei ATCC 6258, were included in each antifungal susceptibility test as quality-control isolates. The MIC interpretive criteria included species-specific Clinical and Laboratory Standards Institute clinical breakpoints for fluconazole, micafungin, and caspofungin (17), as well as epidemiologic cutoff values (ECVs) for voriconazole and amphotericin B (18). Echinocandin resistance was confirmed through DNA sequence analysis of FKS genes to identify resistance hot-spot mutations in FKS1 and FKS2 (19). 
Multidrug resistance was defined as resistance to both fluconazole and echinocandins (2).

\section{Clinical Characteristics}

Candidemia was defined as the isolation of Candida from $\geq 1$ blood culture (20), and cases with invasive candidiasis without candidemia or colonization were excluded. All demographic characteristics and clinical conditions potentially related to candidemia mortality rates at the time of candidemia onset were investigated (21-23). Previous use of antifungal agents was defined as administration within 3 months before the onset of candidemia. A lack of antifungal therapy was defined as no antifungal therapy or treatment with antifungals for $<3$ days; appropriate antifungal therapy was defined as the administration of $\geq 1$ in vitroactive antifungal (according to the susceptibility pattern of the isolate) for $\geq 72$ hours $(23,24)$. Therapeutic failure was defined as either persistence of Candida in the bloodstream despite $\geq 72$ hours of antifungal therapy or development of breakthrough fungemia during treatment with the indicated antifungal agents for $\geq 72$ hours $(23,24)$. All-cause mortality rates were assessed at 30 and 90 days after the first positive blood culture result. Mortality rates also were analyzed for patients with candidemia who were infected with 297 SDD isolates of C. glabrata as controls. This study was approved by the Institutional Review Board of Chonnam National University Hospital (approval no. CNUH-2020-117).

\section{Multilocus Sequence Typing and Molecular Mechanisms} Multilocus sequence typing (MLST) and PDR1 sequencing were performed for all antifungal-resistant isolates of C. glabrata and for 212 F-SDD control isolates by using methods described previously $(14,21,25)$. PDR1 sequences of each isolate were compared and analyzed on the basis of the reference PDR1 sequence of C. glabrata (GenBank accession no. FJ550269) (14). The FKS1 and FKS2 sequences of 79 isolates that exhibited full or intermediate resistance to micafungin (MIC $\geq 0.12 \mathrm{mg} / \mathrm{L}$ ) or caspofungin (MIC $\geq 0.25 \mathrm{mg} / \mathrm{L}$ ) were compared with those of C. glabrata (GenBank reference sequence nos. FKS1 XM_446406 and FKS2 XM_448401) (14). The expression levels of $C g C D R 1, C g C D R 2$, and $C g S N Q 2$ were evaluated for $30 \mathrm{FR}$ isolates of C. glabrata harboring FR-specific Pdr AAS and for 65 F-SDD control isolates without FR-specific Pdr AAS, as described previously $(26,27)$. The cycle threshold $\left(C_{t}\right)$ of each gene was normalized to that of URA3 to determine the $\Delta C_{t}$ value. For all isolates, relative gene expression $\left(\Delta \Delta \mathrm{C}_{\mathrm{T}}\right)$ was reported as fold change calculated as the mean normalized expression level relative to that of C. glabrata ATCC 90030 (fluconazole MIC 8 $\mathrm{mg} / \mathrm{L}$, set as 1.0).

\section{Statistical Analysis}

Quantitative variables are expressed as means with standard deviations, whereas categorical variables are expressed as counts and percentages. Categorical variables were compared by using the $\chi^{2}$ test or Fisher exact test, Student $t$-test or the Mann-Whitney $\mathrm{U}$ test to compare quantitative variables, as appropriate. Cox proportional hazards models were used to evaluate potential risk factors for 30- and 90-day mortality rates by calculating the hazard ratio (HR). The Kaplan-Meier and log-rank (MantelCox) tests were used to calculate the 30- and 90-day survival probabilities in subgroup analyses. All data were analyzed by using SPSS Statistics 26.0 (IBM, https://www.ibm.com). Statistical significance was determined at a level of $\mathrm{p}<0.05$.

\section{Results}

\section{Incidence of Antifungal Resistance}

The annual proportion of C. glabrata BSI isolates among all Candida BSI isolates increased from 11.7\% to $23.9 \%$ (mean $18.6 \%$ ) during the study period (Table 1 ). The rate of fluconazole resistance (MIC $\geq 64 \mathrm{mg} / \mathrm{L}$ ) increased from $0 \%$ (0/68 isolates) to $8.3 \%$ (14/168 isolates) during the study period. Among the 1,158 BSI isolates of C. glabrata, $66(5.7 \%)$ were resistant to fluconazole, $16(1.4 \%)$ were resistant to echinocandin, and $6(0.5 \%)$ were resistant to multiple drugs. Of the 16 echinocandin-resistant isolates, 6 (37.5\%) were also resistant to fluconazole; thus, these isolates were MDR. Isolates of echinocandin-resistant and MDR C. glabrata were initially found in 2013 and then annually from 2016 to 2018. Resistance to amphotericin B (MIC $>2 \mathrm{mg} / \mathrm{L}$ ) was not detected in any isolate, but 79 $(6.8 \%)$ isolates had voriconazole MICs that exceeded the ECV $(0.25 \mathrm{mg} / \mathrm{L})$. All $64 \mathrm{FR}$ isolates were associated with a voriconazole MIC $\geq 0.5 \mathrm{mg} / \mathrm{L}$.

\section{Mortality Rate of FR Candida glabrata BSIs}

The mortality rate for 64 patients with FR C. glabrata BSI isolates was $60.9 \%$ at 30 days (Appendix Table 2). Univariate Cox regression analyses revealed that a high Charlson comorbidity index $(p=0.051)$, liver disease $(p=0.015)$, intensive-care unit admission $(p=0.071)$, severe sepsis $(p=0.039)$, lack of antifungal therapy $(p<0.001)$, azole monotherapy $(p=0.005)$, any combination antifungal therapy $(\mathrm{p}=0.014)$, and appropriate antifungal therapy 
Table 1. Incidence of antifungal resistance in Candida glabrata BSI isolates, based on cultures collected during a multicenter surveillance study, South Korea, 2008-2018*

\begin{tabular}{|c|c|c|c|c|c|c|}
\hline \multirow[b]{2}{*}{$\begin{array}{l}\text { Study } \\
\text { year }\end{array}$} & \multirow[b]{2}{*}{$\begin{array}{l}\text { No. participating } \\
\text { hospitals } \dagger\end{array}$} & \multirow[b]{2}{*}{$\begin{array}{l}\% \text { C. glabrata of all } \\
\text { Candida BSI isolates }\end{array}$} & \multirow[b]{2}{*}{$\begin{array}{l}\text { No. BSI isolates of } \\
\text { C. glabrata tested }\end{array}$} & \multicolumn{3}{|c|}{ No. (\%) C. glabrata BSI isolates $\ddagger$} \\
\hline & & & & $\begin{array}{l}\text { Fluconazole } \\
\text { resistance }\end{array}$ & $\begin{array}{c}\text { Echinocandin } \\
\text { resistance }\end{array}$ & $\begin{array}{l}\text { Multidrug } \\
\text { resistance }\end{array}$ \\
\hline 2008 & 13 & 11.7 & 68 & 0 & 0 & 0 \\
\hline 2009 & 8 & 16.0 & 67 & $4(6.0)$ & 0 & 0 \\
\hline 2010 & 8 & 16.8 & 60 & $4(6.7)$ & 0 & 0 \\
\hline 2011 & 10 & 16.0 & 85 & $4(4.7)$ & 0 & 0 \\
\hline 2012 & 11 & 17.0 & 108 & $3(2.8)$ & 0 & 0 \\
\hline 2013 & 7 & 16.9 & 73 & $4(5.5)$ & $1(1.4)$ & $1(1.4)$ \\
\hline 2014 & 7 & 22.1 & 123 & $11(8.9)$ & 0 & 0 \\
\hline 2015 & 10 & 17.2 & 110 & $5(4.5)$ & $3(2.7)$ & 0 \\
\hline 2016 & 10 & 21.2 & 123 & $4(3.3)$ & $4(3.3)$ & $2(1.6)$ \\
\hline 2017 & 13 & 21.6 & 173 & $13(7.5)$ & $4(2.3)$ & $1(0.6)$ \\
\hline 2018 & 13 & 23.9 & 168 & $14(8.3)$ & $4(2.4)$ & $2(1.2)$ \\
\hline Total & 19 & 18.6 & 1158 & $66(5.7)$ & $16(1.4)$ & $6(0.5)$ \\
\hline
\end{tabular}

${ }^{*} \mathrm{BSI}$, bloodstream infection.

†Hospitals participating in this laboratory-based nationwide multicenter surveillance system differed each year.

¥Antifungal susceptibility was determined by using the Clinical and Laboratory Standards Institute M27-4ED broth microdilution method (16). Interpretive categories of resistance were determined by using Clinical and Laboratory Standards Institute document M60-ED (17). We deposited 76 antifungalresistant isolates of $C$. glabrata in the Korea Collection for Type Culture (KCTC; Jeongeup-si, Korea), including those showing resistance to fluconazole alone (60 isolates, KCTC nos. 37113-37172), echinocandin alone (10 isolates, KCTC nos. 37176-37185), and both fluconazole and echinocandin (6 multidrug-resistant isolates, KCTC nos. 37110-37112, 37173-37175). All 76 isolates were identified as C. glabrata by sequence analysis using the D1/D2 domain (GenBank accession nos. MW349716-90 and MW351777).

§Echinocandin resistance was confirmed by the identification of resistance hot-spot mutations in FKS1 and FKS2 in isolates that exhibited full or intermediate resistance to micafungin ( $\mathrm{MIC} \geq 0.12 \mathrm{mg} / \mathrm{L}$ ) or caspofungin $\mathrm{MIC}(\geq 0.25 \mathrm{mg} / \mathrm{L})$.

ॠMultidrug resistance was defined as resistance to both fluconazole and echinocandins.

$(\mathrm{p}=0.001)$ were associated with the 30-day mortality rate. The 30-day mortality rates were $88.9 \%(8 / 9)$ in patients with azole monotherapy, 69.2\% (9/13) in patients with echinocandin monotherapy, $70 \%$ $(7 / 10)$ in patients with amphotericin B monotherapy, 36.4\% $(8 / 22)$ in patients with combination antifungal therapy, $90 \%(18 / 20)$ in patients with inadequate antifungal therapy, and $47.7 \%(21 / 44)$ in patients with appropriate antifungal therapy. Patients treated with azole monotherapy or inadequate antifungal therapy showed significantly higher 30day mortality rates than those receiving combination therapy or appropriate antifungal therapy (all $\mathrm{p}<0.05)$. In multivariate Cox regression analysis, no independent risk factors for 30-day mortality were identified, but appropriate antifungal therapy (HR 0.304 [95\% CI 0.134-0.689]; $p=0.004$ ) was independently protective with respect to 30 -day mortality. The mortality rate for 64 patients with FR C. glabrata BSI isolates was $78.2 \%$ at 90 days; appropriate antifungal therapy (HR 0.31 [95\% CI 0.138-0.695]; $\mathrm{p}=$ 0.004 ) was the only protective factor with respect to 90-day mortality (Appendix Table 3). Kaplan-Meier survival analysis showed that the mortality dynamics of the FR group (64 patients) decreased during the study period, whereas the F-SDD group (297 patients) exhibited a plateau period of decreasing cumulative survival from 30 to 90 days, which was similar in each of the 4 years of the study period (Figure). The median survival of patients with FR C. glabrata BSI was significantly shorter than that of patients with F-SDD C. glabrata (17 days for FR vs. 90 days for F-SDD; $\mathrm{p}<0.001$ by log-rank test).

\section{MLST Genotypes and AAS in Pdr1p}

MLST revealed that 56.1\% (37/66) of FR, 56.3\% (9/16) of echinocandin-resistant, and 100\% (6/6) of MDR isolates belonged to sequence type (ST) 7 . Table 2 lists the sequencing results for PDR1 and the MLST genotypes for the $66 \mathrm{FR}$ isolates of C. glabrata, as well as 212 control F-SDD isolates. In total, 68 types of AAS in Pdr1p were found in the 278 isolates of C. glabrata tested. When Pdr1p polymorphisms were compared between $\geq 2$ isolates in the same ST ( 257 isolates in 11 STs), excluding 21 STs that were unique to a single isolate, all 50 ST3 isolates harbored the same 3 Pdr1p AAS (P76S, P143T, and D243N), all 8 ST55 isolates harbored E259G, and all 4 ST59 isolates harbored T745A, irrespective of FR. However, these 5 Pdr AAS were not found in any ST7 isolates or any isolates of the other 7 ST groups, each of which contained $\geq 2$ isolates. Excluding 5 Pdr1 AAS (P76S, P143T, D243N, E259G, and T745A), 1 additional Pdr1p AAS was found in each of 2 F-SDD isolates $(0.9 \%, n=212) ; 1$ (59 FR isolates) or 2 (6 FR isolates) additional Pdr1p AAS was found in 65/66 (98.5\%) FR isolates.

\section{AAS in Pdr1p Shown in Only FR isolates}

Each of the 49 Pdr1p AAS was found alone in 59 FR isolates of C. glabrata and their MLST genotypes (Table 3). In 38 (64.4\%) isolates, AAS were found in 3 domains of Pdr1p, the inhibition (33.9\%), fungal-specific 
transcription factor $(11.9 \%)$, and activation (18.6\%) domains; AAS were outside the main domains in 21 $(35.6 \%)$ isolates. Of 49 Pdr1p AAS, 16 were described previously for FR isolates, whereas 33 (67.3\%) were newly found in this study. Of these potentially novel Pdr1p AAS, 5 (P327L, G346S, H576Y, T607A, and G788W) were shared by 2 isolates with the same genotype. Among these, 2 AAS (G346S [ST2] and H576Y [ST7]), were shared by 2 isolates from the same hospital in the same year. Quantitative reverse transcription PCR revealed that $30 \mathrm{FR}$ isolates harboring the Pdr mutation exhibited significantly higher mean expression levels of $C g C D R 1, C g C D R 2$, and $C g S N Q 2$ than 65 control F-SDD isolates (FR vs. F-SDD; 11.5- vs. 1.5-fold for $C g C D R 1, \mathrm{p}<0.0001$; 43.4- vs. 27.0-fold for CgCDR2, $\mathrm{p}=0.0408$; and 4.9- vs. 3.5-fold for CgSNQ2, $\mathrm{p}=0.0174)$ (Appendix Figure).

\section{Discussion}

After C. albicans, C. glabrata is the most common Candida species isolated from BSI in North America and in countries of central and northern Europe $(1,4)$. C. glabrata was the fourth most common BSI-causing Candida species in many countries in Asia besides South Korea $(6,28,29)$; however, increasing rates of $C$. glabrata with FR have been reported in China (30), and this strain is now the second most common species in South Korea (31). In this study, the FR rate of BSI isolates of C. glabrata were found to have increased from $0 \%(0 / 68)$ in 2008 to $8.3 \%(14 / 168)$ in 2018. No C. glabrata isolate collected during 2008-2012 was

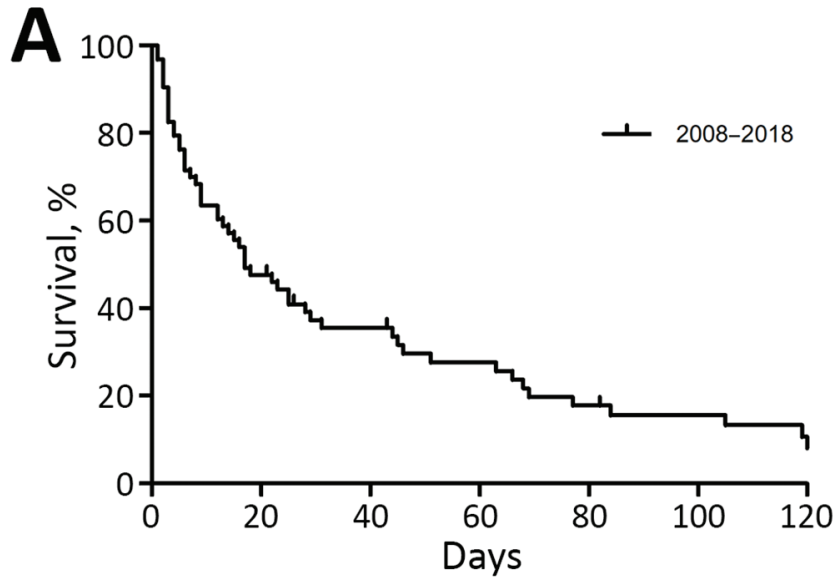

resistant to echinocandins, whereas $2 \%-3 \%$ were resistant to echinocandins during 2015-2018. The emergence of echinocandin-resistant BSI isolates of C. glabrata in South Korea might reflect the increased use of echinocandin antifungals as the initial option for candidemia after insurance coverage for echinocandins began in 2014 (32). Of 16 echinocandin-resistant isolates, $6(37.5 \%)$ were also resistant to fluconazole, indicating multidrug resistance. Overall, our 11-year nationwide surveillance revealed an increasing incidence of C. glabrata causing BSI and an increasing propensity for development of antifungal resistance in South Korea, consistent with surveillance data from other countries $(1,2,4,5,30)$.

Data are scarce regarding the mortality rates for patients with candidemia who are infected with FR C. glabrata BSI isolates. The 30-day mortality rates in patients infected with C. glabrata BSI isolates are $21.3 \%-48.6 \%(16,33-37)$ but can reach $50 \%-60 \%$ among patients in intensive care units $(38,39)$. However, few FR C. glabrata isolates were included in previous studies. We found that FR BSI isolates of C. glabrata in South Korea were associated with significantly higher 30-day (60.9\%) and 90-day (78.2\%) mortality rates, compared to BSIs caused by F-SDD strains (30-day mortality rate $36.4 \%$, 90-day mortality rate $43.8 \%$ ). The mortality dynamics of FR isolates indicated a rapid rise in cumulative mortality from 7 to 90 days after BSI onset. This mortality dynamic was distinct from that of patients with F-SDD BSIs, who exhibited a steady curve after 60 days, consistent

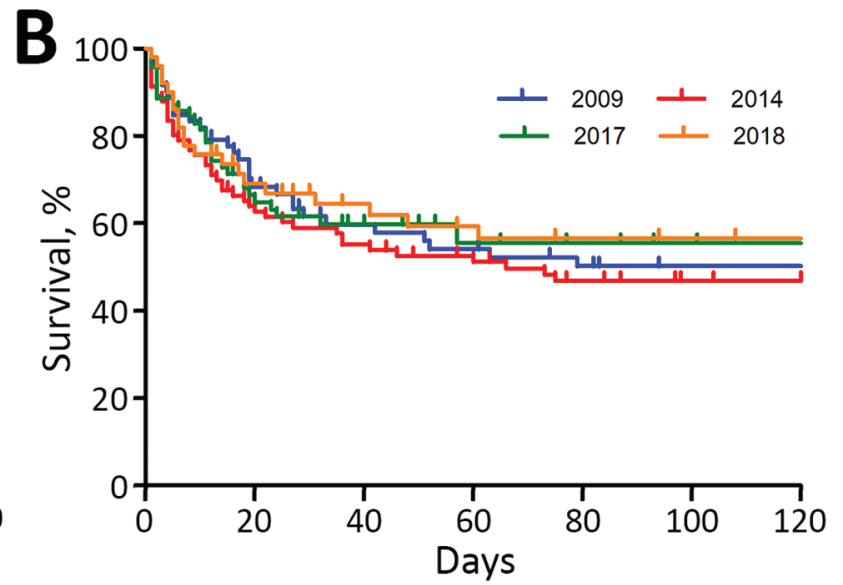

Figure. Kaplan-Meier and log-rank (Mantel-Cox) pairwise analyses of survival of patients with Candida glabrata candidemia, based on patient data and cultures collected during a multicenter surveillance study, South Korea, 2008-2018. A) Cumulative survival curves of 64 patients infected with fluconazole-resistant (FR) bloodstream infection (BSI) isolates. The cumulative mortality rates of 64 patients infected with FR C. glabrata BSIs increased over time (day 7 [29.7\%], day 30 [60.9\%], day 60 [68.8\%], and day 90 [78.1\%]). B) Cumulative survival curves of patients infected with fluconazole-susceptible dose-dependent (F-SDD) BSI isolates (297 patients total) in 2009 (75 patients in 6 hospitals), 2014 (97 patients in 7 hospitals), 2017 (75 patients in 9 hospitals), and 2018 (50 patients in 8 hospitals). The 30 -day mortality rate of the F-SDD group was $34.7 \%$ in $2010,39.2 \%$ in $2014,37.3 \%$ in 2017 , and $32.0 \%$ in 2018 . The cumulative mortality rates of 297 patients infected with F-SDD BSI isolates of $C$. glabrata were found to be $18.5 \%$ at day $7(p=0.084)$, $36.4 \%$ at day $30(p=0.001), 41.8 \%$ at day $60(p<0.001)$, and $43.8 \%$ at day $90(p<0.001)$. 
with previous reports of C. glabrata BSIs $(34,40)$. The median survival of patients with FR C. glabrata BSIs (17 days) was also significantly shorter than that of patients with F-SDD C. glabrata BSIs (90 days). These findings are consistent with the results in a recent report regarding C. glabrata BSIs in South Korea, which showed that a high fluconazole MIC was associated with a poor outcome, although only 5 isolates in that study were FR (37).

In this study, MLST revealed that $56.1 \%$ of FR and $56.3 \%$ of echinocandin-resistant BSI isolates belonged to ST7, which accords with ST7 being the most common MLST genotype $(47.8 \%)$ in South Korea (21). We found that $100 \%(6 / 6)$ of MDR isolates belonged to ST7, which harbored the V239L mutation in the mismatch repair gene (MSH2) associated with hypermutability $(21,25)$. Given that the utility of $\mathrm{MSH} 2$ gene mutations as antifungal-resistance markers remains controversial $(41,42)$, further surveillance studies are needed. To date, few studies have been conducted on MLST genotype-specific differences in Pdr1p polymorphism among C. glabrata BSI isolates. We found that all 50 isolates of ST3 harbored the same Pdr1p AAS (P76S/P143T/
D243N), all 7 isolates of ST55 harbored E259G, and all 4 isolates of ST59 harbored T745A, suggesting the presence of MLST genotype-specific Pdr1p AAS. P76S/P143T/D243N in Pdr1p was found to be common in China, Iran, and Australia $(13,14,43,44)$, which accords with the high prevalence of ST3 in the study collections. Thus, the results of this study suggest that 5 Pdr1p AAS are MLST genotype-specific; because these AAS were found in both FR and F-SDD isolates, we confirmed that they cannot be responsible for azole resistance.

A single-point mutation in PDR1 can contribute to azole resistance in C. glabrata $(7,8)$. Our results show that, in FR isolates, AAS are scattered throughout the entire protein without distinct hotspots, as reported previously $(7,13,41,45)$. Therefore, determining whether a certain Pdr1p AAS is a GOF mutation is difficult without data from gene editing experiments for all variable regions. A previous study identified 57 FR-specific AAS by comparing azole-susceptible and azole-resistant matched isolates recovered from different clinical specimens (7). Furthermore, 91\% $(74 / 81)$ of FR isolates from BSIs or vaginal infections contained a Pdr1 mutation, compared with 5.6\%

\begin{tabular}{|c|c|c|c|c|c|c|c|c|c|c|c|}
\hline \multirow{2}{*}{$\begin{array}{l}\text { MLST } \\
\text { genotype }\end{array}$} & \multirow{2}{*}{$\begin{array}{l}\text { Fluconazole } \\
\text { susceptibility }\end{array}$} & \multirow{2}{*}{$\begin{array}{c}\text { No. } \\
\text { isolates } \\
\text { tested }\end{array}$} & \multirow{2}{*}{$\begin{array}{l}\text { No. with } \\
\text { echinocandin } \\
\text { resistance }\end{array}$} & \multicolumn{5}{|c|}{$\begin{array}{l}\text { No. isolates with } 5 \text { Pdr1p AAS found in } \\
\text { both FR and F-SDD isolates }\end{array}$} & \multicolumn{3}{|c|}{$\begin{array}{l}\text { No. isolates with additional Pdr1p } \\
\text { AAS except for } 5 \text { Pdr1p AAS }\end{array}$} \\
\hline & & & & P76S & $\mathrm{P} 143 \mathrm{~T}$ & D243N & E259G & $\mathrm{T} 745 \mathrm{~A}$ & 1 & 2 & Total \\
\hline ST7 & $\begin{array}{c}\text { FR } \\
\text { F-SDD }\end{array}$ & $\begin{array}{l}37 \\
98\end{array}$ & $\begin{array}{c}6 \dagger \\
3\end{array}$ & & & & & & $\begin{array}{c}34 \\
0\end{array}$ & 3 & $\begin{array}{c}37 \\
0\end{array}$ \\
\hline ST3 & $\begin{array}{c}\text { FR } \\
\text { F-SDD }\end{array}$ & $\begin{array}{c}7 \\
43\end{array}$ & $\begin{array}{l}0 \\
1\end{array}$ & $\begin{array}{c}7 \\
43\end{array}$ & $\begin{array}{c}7 \\
43\end{array}$ & $\begin{array}{c}7 \\
43\end{array}$ & & & $\begin{array}{l}6 \\
0\end{array}$ & 1 & $\begin{array}{l}7 \\
0\end{array}$ \\
\hline ST26 & $\begin{array}{c}\text { FR } \\
\text { F-SDD }\end{array}$ & $\begin{array}{c}7 \\
10 \\
\end{array}$ & $\begin{array}{l}0 \\
1\end{array}$ & & & & & & $\begin{array}{l}6 \\
0\end{array}$ & & $\begin{array}{l}6 \\
0\end{array}$ \\
\hline ST22 & $\begin{array}{c}\text { FR } \\
\text { F-SDD }\end{array}$ & $\begin{array}{c}1 \\
16\end{array}$ & $\begin{array}{l}0 \\
1\end{array}$ & & & & & & $\begin{array}{l}1 \\
0\end{array}$ & & $\begin{array}{l}1 \\
0\end{array}$ \\
\hline ST10 & $\begin{array}{c}\text { FR } \\
\text { F-SDD }\end{array}$ & $\begin{array}{l}2 \\
9\end{array}$ & $\begin{array}{l}0 \\
0\end{array}$ & & & & & & $\begin{array}{l}2 \\
0\end{array}$ & & $\begin{array}{l}2 \\
0\end{array}$ \\
\hline ST55 & $\begin{array}{c}\text { FR } \\
\text { F-SDD }\end{array}$ & $\begin{array}{l}2 \\
6\end{array}$ & $\begin{array}{l}0 \\
1\end{array}$ & & & & $\begin{array}{l}2 \\
6\end{array}$ & & $\begin{array}{l}2 \\
1 \\
\end{array}$ & & $\begin{array}{l}2 \\
1 \\
\end{array}$ \\
\hline ST2 & $\begin{array}{c}\text { FR } \\
\text { F-SDD }\end{array}$ & $\begin{array}{l}2 \\
3 \\
\end{array}$ & $\begin{array}{l}0 \\
0\end{array}$ & & & & & & $\begin{array}{l}2 \\
0\end{array}$ & & $\begin{array}{l}2 \\
0\end{array}$ \\
\hline ST6 & $\begin{array}{c}\text { FR } \\
\text { F-SDD }\end{array}$ & $\begin{array}{l}1 \\
5\end{array}$ & $\begin{array}{l}0 \\
2\end{array}$ & & & & & & $\begin{array}{l}1 \\
0\end{array}$ & & $\begin{array}{l}1 \\
0\end{array}$ \\
\hline ST59 & $\begin{array}{c}\text { FR } \\
\text { F-SDD }\end{array}$ & $\begin{array}{l}1 \\
3 \\
\end{array}$ & $\begin{array}{l}0 \\
1\end{array}$ & & & & & $\begin{array}{l}1 \\
3 \\
\end{array}$ & $\begin{array}{l}1 \\
0\end{array}$ & & $\begin{array}{l}1 \\
0\end{array}$ \\
\hline ST1 & FR & 2 & 0 & & & & & & 2 & & 2 \\
\hline ST12 & F-SDD & 2 & 0 & & & & & & 0 & & 0 \\
\hline Other STs $\ddagger$ & $\begin{array}{c}\text { FR } \\
\text { F-SDD }\end{array}$ & $\begin{array}{c}4 \\
17 \\
\end{array}$ & $\begin{array}{l}0 \\
0 \\
\end{array}$ & 2 & 2 & 2 & 1 & & $\begin{array}{l}2 \\
1 \\
\end{array}$ & 2 & $\begin{array}{l}4 \\
1 \\
\end{array}$ \\
\hline Total, no. (\%) & $\begin{array}{c}\text { FR } \\
\text { F-SDD }\end{array}$ & $\begin{array}{c}66 \\
212 \\
\end{array}$ & $\begin{array}{c}6 \\
10 \\
\end{array}$ & $\begin{array}{c}7 \\
45 \\
\end{array}$ & $\begin{array}{c}7 \\
45 \\
\end{array}$ & $\begin{array}{c}7 \\
45 \\
\end{array}$ & $\begin{array}{l}3 \\
6 \\
\end{array}$ & $\begin{array}{l}1 \\
3 \\
\end{array}$ & $\begin{array}{l}59 \\
2 \pi \\
\end{array}$ & $6 \S$ & $\begin{array}{c}65(98.5) \\
2(0.9) \\
\end{array}$ \\
\hline $\begin{array}{l}\text { *AAS, amino aci } \\
\text { sequence typing } \\
\text { †All } 6 \text { isolates sh } \\
\text { †Includes } 21 \mathrm{ST} \\
\text { §Each of } 6 \mathrm{FR} \text { is } \\
\text { G189V/E340G [ } \\
\text { TTwo F-SDD iso }\end{array}$ & $\begin{array}{l}\text { substitution; BS } \\
\text { ST, sequence ty } \\
\text { owed multidrug r } \\
\text { that were each } \\
\text { olates harbored } 2 \\
\text { ther ST], and L3 } \\
\text { lates harbored ad }\end{array}$ & $\begin{array}{l}\text { I, bloodstre } \\
\text { pe. } \\
\text { esistance, } \\
\text { unique to a } \\
2 \text { additional } \\
66 \mathrm{P} / \mathrm{E} 555 \mathrm{D} \\
\text { Iditional Pd }\end{array}$ & $\begin{array}{l}\text { am infection; FR } \\
\text { defined as resist } \\
\text { single isolate. } \\
\text { Pdr1 AAS (E340 } \\
\text { [other ST]). } \\
\text { r1 AAS (V502I [s }\end{array}$ & $\begin{array}{l}\text { flucon } \\
\text { nce to } \\
\text { G/D919 } \\
\text { T55] ar }\end{array}$ & $\begin{array}{l}\text { le-resis } \\
\text { h flucon } \\
\text { ST7], Y }\end{array}$ & $\begin{array}{l}\text { int; F-S } \\
\text { zole anc } \\
56 \mathrm{C} / \mathrm{F} 58\end{array}$ & $\begin{array}{l}\text { flucon } \\
\text { chinoca } \\
\text { [ST7], }\end{array}$ & $\begin{array}{l}\text { ole-sus } \\
\text { dins. } \\
32 S / G\end{array}$ & $\begin{array}{l}\text { e dos } \\
\text { [ST7] }\end{array}$ & & $\begin{array}{l}\text { T, multilocus } \\
3] \text {, }\end{array}$ \\
\hline
\end{tabular}


Table 3. Pdr1 AAS in $59 \mathrm{FR}$ isolates of Candida glabrata BSI isolates and their MLST genotypes, based on cultures collected during a multicenter surveillance study, South Korea, 2008-2018*

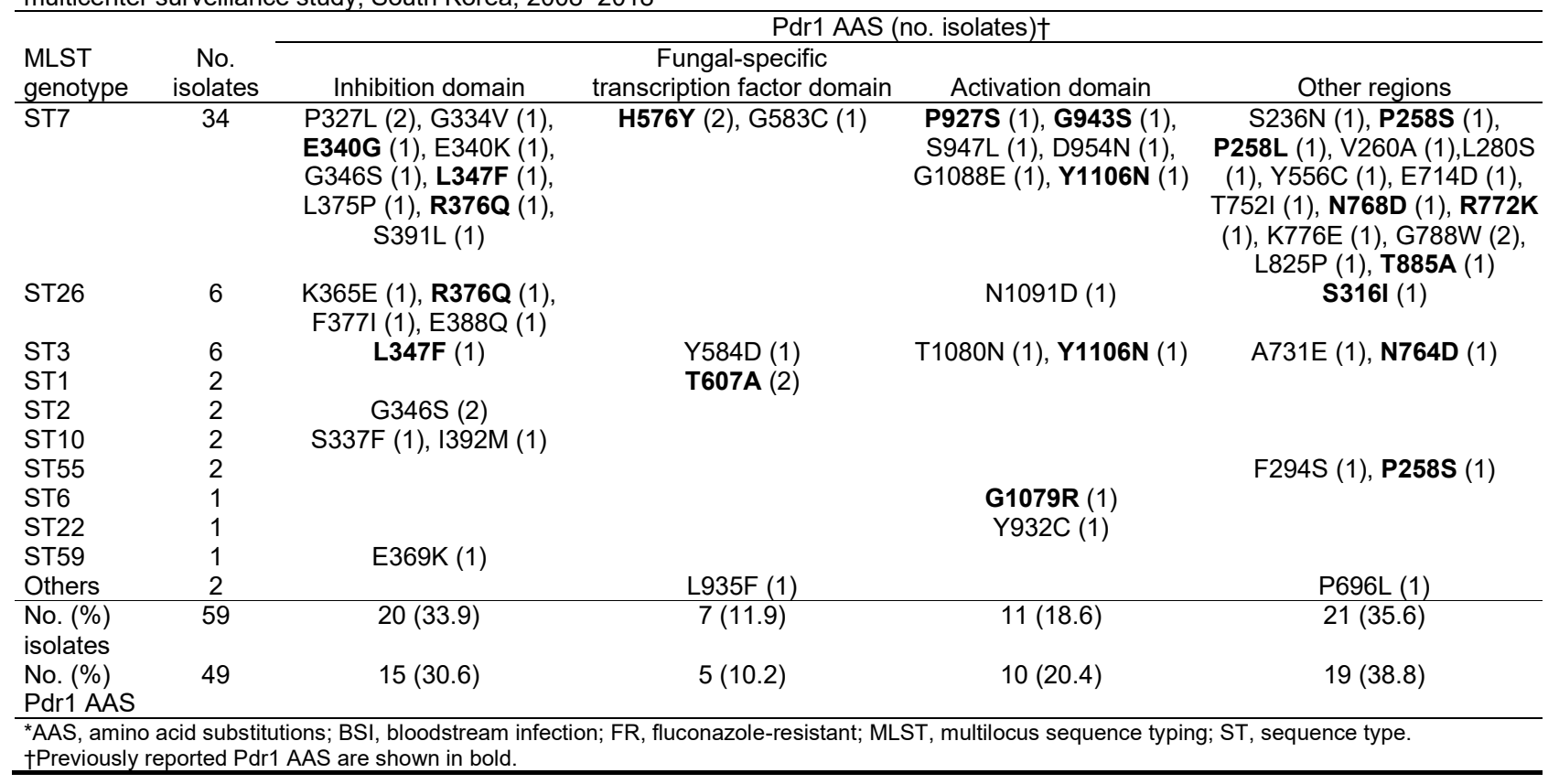

$(1 / 18)$ of F-SDD isolates (25). In our study, we found that $98.5 \%(65 / 66)$ of FR BSI isolates and $0.9 \%(2 / 212)$ of F-SDD BSI isolates harbored an additional 1 or 2 Pdr1p AAS after exclusion of 5 genotype-specific AAS (P76S, P143T D243N, E259G, and T745A). After exclusion of 6 additional FR isolates that harbored 2 Pdr1p AAS (because determining which of the 2 AAS was critical for fluconazole resistance was difficult to determine), we found 49 Pdr1p AAS that were present alone in 59 FR isolates, strongly suggesting that these AAS were FR-specific. Of the 49 Pdr1p AAS, 16 have been described for FR isolates $(7,13,14,25,43-$ 46). In this study, FR isolates exhibited higher mean CgCDR1, CgCDR2, or CgSNQ2 expression levels, compared with F-SDD isolates; all FR C. glabrata isolates were also resistant to voriconazole (MIC $\geq 0.5$ $\mathrm{mg} / \mathrm{L}$ ), implying that fluconazole and voriconazole resistance are governed by the same mechanism (i.e., a GOF mutation in the transcription factor for Pdr1p) $(7,8)$. Overall, our findings demonstrate that most FR BSI isolates of C. glabrata in South Korea harbor FRspecific Pdr1p AAS.

The cause of the high mortality rate associated with FR C. glabrata BSIs remains unclear. In this study, we focused on FR-specific Pdr1p AAS. PDR1 mutations are associated with increased virulence of C. glabrata, expression of adhesins, and adherence to host epithelial cells $(7,12,47,48)$. The fungal loads in the kidney, spleen, and liver were higher in mice infected with the FR Pdr1 mutant of C. glabrata than in mice infected with F-SDD isolates (12). C. glabrata might persist in the body by replicating inside phagocytes, eventually leading to cell lysis, rather than by active escape (the method used by C. albicans) $(47,49)$. This process might partly explain the elevated cumulative mortality rate for patients with Pdr1 mutants. Appropriate antifungal therapy was the only independently associated protective factor, with respect to 30- and 90-day mortality rates, in patients infected with FR C. glabrata isolates. In patients who received inadequate antifungal therapy and azole monotherapy, the 30-day mortality rates were 90\% (antifungal therapy) and $88.9 \%$ (azole monotherapy), which were significantly higher than those of the patients receiving combination therapy (36.4\%) or appropriate antifungal therapy (47.7\%). Previous antifungal exposure was not an independent risk factor for death among patients with FR isolates, although it was identified in $62.5 \%(40 / 64)$ of patients. Given that previous antifungal exposure is a risk factor for antifungalresistant Candida BSI (50), further studies including FSDD C. glabrata BSIs might elucidate the relationship between previous antifungal exposure and death. Taken together, these findings suggest that the high mortality rate associated with FR C. glabrata BSIs can be explained by the combination of FR and the virulence of Pdr1 mutants.

The first limitation of our study is that a Candida species might develop resistance within a patient during antifungal therapy; such resistance can be iden- 
tified through serial isolates, but we tested only the first isolate from each patient during 2016-2018. Second, our results did not show that FR, PDR1 mutants, or previous antifungal exposure were independent risk factors for death in patients with C. glabrata BSIs. A total of 1,158 nonduplicate BSI isolates of C. glabrata from 19 university hospitals in South Korea were obtained during the 11-year study period, and the hospitals participating differed each year; therefore, we could not select an appropriate control group of F-SDD isolates. These limitations were partly overcome in a recent study involving 197 adult patients with C. glabrata BSI during January 2010-February 2016 at 7 university hospitals in South Korea. In that study, FR was shown to be associated with the 30-day mortality rate in a multivariate analysis (37). Third, only limited numbers of patients infected with F-SDD BSI isolates of C. glabrata were included in our mortality analysis. Nevertheless, we included a total of 297 patients infected with F-SDD BSI isolates of C. glabrata, which included all patients with C. glabrata from the participating hospitals in 2010, 2014, 2017, and 2018. The 30-day mortality rates of patients infected with F-SDD C. glabrata isolates were similar among those 4 years $(32.0 \%-39.2 \%)$, despite differences in participating hospitals and collection periods; the 30day mortality rate was similar to those reported in previous studies $(21,33-37)$.

In conclusion, we demonstrated that nearly all FR BSI isolates of C. glabrata in South Korea harbored FR-specific Pdr1p mutations by excluding MLST genotype-specific Pdr1p AASs and that the isolates were associated with higher 30-day (60.9\%) and 90day $(78.2 \%)$ mortality rates. These results suggest that Pdr1 mutants are associated with a risk for death in such patients. In addition, appropriate antifungal therapy was the only independent protective factor against death in patients with FR isolates. Because of the increasing prevalence of FR BSI isolates of C. glabrata worldwide, improved detection and appropriate antifungal treatments are critical.

This research was supported by the Basic Science Research Program through the National Research Foundation of South Korea funded by the Ministry of Education (grant no. NRF-2019R1A2C1004644).

\section{About the Author}

Dr. Won is an associate professor at Chonnam National University Hospital and Chonnam National University Medical School, Gwangju, South Korea. Her interests are the epidemiology, molecular identification, and resistance mechanisms of invasive fungal infections and medical parasitology. Dr. Choi works at the laboratory of medical mycology, focusing on invasive fungal infections, at Chonnam National University Hospital. She has conducted collaborative studies of the epidemiology of candidemia and related molecular resistance mechanisms.

\section{References}

1. Arendrup MC. Epidemiology of invasive candidiasis. Curr Opin Crit Care. 2010;16:445-52. https:/ /doi.org/10.1097/ MCC.0b013e32833e84d2

2. Arendrup MC, Patterson TF. Multidrug-resistant Candida: epidemiology, molecular mechanisms, and treatment. J Infect Dis. 2017;216(Suppl_3):S445-51. https://doi.org/10.1093/ infdis/jix131

3. Jensen RH, Johansen HK, Søes LM, Lemming LE, Rosenvinge FS, Nielsen L, et al. Posttreatment antifungal resistance among colonizing Candida isolates in candidemia patients: results from a systematic multicenter study. Antimicrob Agents Chemother. 2015;60:1500-8. https:// doi.org/10.1128/AAC.01763-15

4. Pfaller MA, Diekema DJ, Turnidge JD, Castanheira M, Jones RN. Twenty years of the SENTRY antifungal surveillance program: results for Candida species from 1997-2016. Open Forum Infect Dis. 2019;6(Suppl 1):S79-94. https://doi.org/10.1093/ofid/ofy358

5. Chapman B, Slavin M, Marriott D, Halliday C, Kidd S, Arthur I, et al.; Australian and New Zealand Mycoses Interest Group. Changing epidemiology of candidaemia in Australia. J Antimicrob Chemother. 2017;72:1103-8. https://doi.org/10.1093/jac/dkx047

6. Tan TY, Hsu LY, Alejandria MM, Chaiwarith R, Chinniah T, Chayakulkeeree M, et al. Antifungal susceptibility of invasive Candida bloodstream isolates from the Asia-Pacific region. Med Mycol. 2016;54:471-7. https://doi.org/10.1093/ mmy/myv114

7. Ferrari S, Ischer F, Calabrese D, Posteraro B, Sanguinetti M, Fadda G, et al. Gain of function mutations in CgPDR1 of Candida glabrata not only mediate antifungal resistance but also enhance virulence. PLoS Pathog. 2009;5:e1000268. https:/ / doi.org/10.1371/journal.ppat.1000268

8. Tsai HF, Krol AA, Sarti KE, Bennett JE. Candida glabrata PDR1, a transcriptional regulator of a pleiotropic drug resistance network, mediates azole resistance in clinical isolates and petite mutants. Antimicrob Agents Chemother. 2006;50:1384-92. https:/ / doi.org/10.1128/AAC.50.4.13841392.2006

9. Hull CM, Parker JE, Bader O, Weig M, Gross U, Warrilow AG, et al. Facultative sterol uptake in an ergosterol-deficient clinical isolate of Candida glabrata harboring a missense mutation in ERG11 and exhibiting cross-resistance to azoles and amphotericin B. Antimicrob Agents Chemother. 2012;56:4223-32. https://doi.org/10.1128/AAC.06253-11

10. Abbes S, Mary C, Sellami H, Michel-Nguyen A, Ayadi A, Ranque S. Interactions between copy number and expression level of genes involved in fluconazole resistance in Candida glabrata. Front Cell Infect Microbiol. 2013;3:74. https://doi.org/10.3389/fcimb.2013.00074

11. Vu BG, Moye-Rowley WS. Construction and use of a recyclable marker to examine the role of major facilitator superfamily protein members in Candida glabrata drug resistance phenotypes. MSphere. 2018;3:e00099-18. https:/ / doi.org/10.1128/mSphere.00099-18

12. Ferrari S, Sanguinetti M, Torelli R, Posteraro B, Sanglard D. Contribution of CgPDR1-regulated genes in enhanced 
virulence of azole-resistant Candida glabrata. PLoS One. 2011;6:e17589. https:// doi.org/10.1371/journal. pone.0017589

13. Hou X, Xiao M, Wang H, Yu SY, Zhang G, Zhao Y, et al. Profiling of PDR1 and MSH2 in Candida glabrata bloodstream isolates from a multicenter study in China. Antimicrob Agents Chemother. 2018;62:e00153-18. https://doi.org/ 10.1128/AAC.00153-18

14. Arastehfar A, Daneshnia F, Zomorodian K, Najafzadeh MJ, Khodavaisy S, Zarrinfar $\mathrm{H}$, et al. Low level of antifungal resistance in Iranian isolates of Candida glabrata recovered from blood samples in a multicenter study from 2015 to 2018 and potential prognostic values of genotyping and sequencing of PDR1. Antimicrob Agents Chemother. 2019;63:e02503-18. https:/ / doi.org/10.1128/AAC.02503-18

15. Hou X, Xiao M, Chen SC, Wang H, Yu SY, Fan X, et al. Identification and antifungal susceptibility profiles of Candida nivariensis and Candida bracarensis in a multi-center Chinese collection of yeasts. Front Microbiol. 2017;8:5. https://doi.org/10.3389/fmicb.2017.00005

16. Clinical and Laboratory Standards Institute. M27 reference method for broth dilution antifungal susceptibility testing of yeasts. 4th ed. Wayne (PA): Clinical and Laboratory Standards Institute; 2017.

17. Clinical and Laboratory Standards Institute. Performance standards for antifungal susceptibility testing of Yeasts. 1st ed. CLSI supplement M60. Wayne (PA): Clinical and Laboratory Standards Institute; 2017.

18. Clinical and Laboratory Standards Institute. Epidemiological cutoff values for antifungal susceptibility testing. 2nd ed. CLSI supplement M59. Wayne (PA): Clinical and Laboratory Standards Institute; 2018.

19. Rivero-Menendez O, Navarro-Rodriguez P, Bernal-Martinez L, Martin-Cano G, Lopez-Perez L, Sanchez-Romero I, et al. Clinical and laboratory development of echinocandin resistance in Candida glabrata: molecular characterization. Front Microbiol. 2019;10:1585. https://doi.org/10.3389/ fmicb.2019.01585

20. Pappas PG, Kauffman CA, Andes DR, Clancy CJ, Marr KA, Ostrosky-Zeichner L, et al. Executive summary: clinical practice guideline for the management of candidiasis: 2016 update by the Infectious Diseases Society of America. Clin Infect Dis. 2016;62:409-17. https://doi.org/10.1093/cid/civ1194

21. Byun SA, Won EJ, Kim MN, Lee WG, Lee K, Lee HS, et al. Multilocus sequence typing (MLST) genotypes of Candida glabrata bloodstream isolates in Korea: association with antifungal resistance, mutations in mismatch repair gene (Msh2), and clinical outcomes. Front Microbiol. 2018;9:1523. https://doi.org/10.3389/fmicb.2018.01523

22. Kim MN, Shin JH, Sung H, Lee K, Kim EC, Ryoo N, et al. Candida haemulonii and closely related species at 5 university hospitals in Korea: identification, antifungal susceptibility, and clinical features. Clin Infect Dis. 2009;48:e57-61. https://doi.org/10.1086/597108

23. De Rosa FG, Trecarichi EM, Montrucchio C, Losito AR, Raviolo S, Posteraro B, et al. Mortality in patients with early- or late-onset candidaemia. J Antimicrob Chemother. 2013;68:927-35. https://doi.org/10.1093/jac/dks480

24. Nguyen MH, Clancy CJ, Yu VL, Yu YC, Morris AJ, Snydman DR, et al. Do in vitro susceptibility data predict the microbiologic response to amphotericin B? Results of a prospective study of patients with Candida fungemia. J Infect Dis. 1998;177:425-30. https://doi.org/10.1086/514193

25. Healey KR, Zhao Y, Perez WB, Lockhart SR, Sobel JD, Farmakiotis D, et al. Prevalent mutator genotype identified in fungal pathogen Candida glabrata promotes multi-drug resistance. Nat Commun. 2016;7:11128. https:/ / doi.org/ 10.1038/ncomms11128

26. Niimi M, Nagai $Y$, Niimi K, Wada S, Cannon RD, Uehara $Y$, et al. Identification of two proteins induced by exposure of the pathogenic fungus Candida glabrata to fluconazole. J Chromatogr B Analyt Technol Biomed Life Sci. 2002;782:245-52. https:// doi.org/10.1016/S15700232(02)00668-2

27. Sanguinetti M, Posteraro B, Fiori B, Ranno S, Torelli R, Fadda G. Mechanisms of azole resistance in clinical isolates of Candida glabrata collected during a hospital survey of antifungal resistance. Antimicrob Agents Chemother. 2005; 49:668-79. https://doi.org/10.1128/AAC.49.2.668-679.2005

28. Won EJ, Shin JH, Choi MJ, Lee WG, Park YJ, Uh Y, et al. Antifungal susceptibilities of bloodstream isolates of Candida species from nine hospitals in Korea: application of new antifungal breakpoints and relationship to antifungal usage. PLoS One. 2015;10:e0118770. https://doi.org/10.1371/ journal.pone.0118770

29. Xiao M, Sun ZY, Kang M, Guo DW, Liao K, Chen SC, et al.; China Hospital Invasive Fungal Surveillance Net (CHIF-NET) Study Group. Five-year national surveillance of invasive candidiasis: species distribution and azole susceptibility from the China Hospital Invasive Fungal Surveillance Net (CHIF-NET) Study. J Clin Microbiol. 2018;56:e00577-18. https:// doi.org/10.1128/JCM.00577-18

30. Hou X, Xiao M, Chen SC, Kong F, Wang H, Chu YZ, et al. Molecular epidemiology and antifungal susceptibility of Candida glabrata in China (August 2009 to July 2014): a multi-center study. Front Microbiol. 2017;8:880. https://doi.org/10.3389/fmicb.2017.00880

31. Ko JH, Jung DS, Lee JY, Kim HA, Ryu SY, Jung SI, et al. Changing epidemiology of non-albicans candidemia in Korea. J Infect Chemother. 2019;25:388-91. https://doi.org/ 10.1016/j.jiac.2018.09.016

32. Choi H, Kim JH, Seong H, Lee W, Jeong W, Ahn JY, et al. Changes in the utilization patterns of antifungal agents, medical cost and clinical outcomes of candidemia from the health-care benefit expansion to include newer antifungal agents. Int J Infect Dis. 2019;83:49-55. https:// doi.org/10.1016/j.ijid.2019.03.039

33. Ruan SY, Huang YT, Chu CC, Yu CJ, Hsueh PR. Candida glabrata fungaemia in a tertiary centre in Taiwan: antifungal susceptibility and outcomes. Int J Antimicrob Agents. 2009;34:236-9. https:// doi.org/10.1016/ j.ijantimicag.2009.02.021

34. Horn DL, Neofytos D, Anaissie EJ, Fishman JA, Steinbach WJ, Olyaei AJ, et al. Epidemiology and outcomes of candidemia in 2019 patients: data from the prospective antifungal therapy alliance registry. Clin Infect Dis. 2009;48:1695-703. https://doi.org/10.1086/599039

35. Lee I, Morales KH, Zaoutis TE, Fishman NO, Nachamkin I, Lautenbach E. Clinical and economic outcomes of decreased fluconazole susceptibility in patients with Candida glabrata bloodstream infections. Am J Infect Control. 2010;38:740-5 https://doi.org/10.1016/j.ajic.2010.02.016

36. Eschenauer GA, Carver PL, Patel TS, Lin SW, Klinker KP, Pai MP, et al. Survival in patients with Candida glabrata bloodstream infection is associated with fluconazole dose. Antimicrob Agents Chemother. 2018;62:e02566-17. https://doi.org/10.1128/AAC.02566-17

37. Ko JH, Peck KR, Jung DS, Lee JY, Kim HA, Ryu SY, et al. Impact of high MIC of fluconazole on outcomes of Candida glabrata bloodstream infection: a retrospective multicenter cohort study. Diagn Microbiol Infect Dis. 2018;92:127-32. https://doi.org/10.1016/j.diagmicrobio.2018.05.001 
38. Tortorano AM, Dho G, Prigitano A, Breda G, Grancini A, Emmi V, et al.; ECMM-FIMUA Study Group. Invasive fungal infections in the intensive care unit: a multicentre, prospective, observational study in Italy (2006-2008). Mycoses. 2012;55:73-9. https://doi.org/10.1111/ j.1439-0507.2011.02044.x

39. Lortholary O, Renaudat C, Sitbon K, Madec Y, Denoeud-Ndam L, Wolff M, et al.; French Mycosis Study Group. Worrisome trends in incidence and mortality of candidemia in intensive care units (Paris area, 2002-2010). Intensive Care Med. 2014;40:1303-12. https:/ / doi. org/10.1007/s00134-014-3408-3

40. Pfaller MA, Andes DR, Diekema DJ, Horn DL, Reboli AC, Rotstein C, et al. Epidemiology and outcomes of invasive candidiasis due to non-albicans species of Candida in 2,496 patients: data from the Prospective Antifungal Therapy (PATH) registry 2004-2008. PLoS One. 2014;9:e101510. https://doi.org/10.1371/journal.pone.0101510

41. Singh A, Healey KR, Yadav P, Upadhyaya G, Sachdeva N, Sarma S, et al. Absence of azole or echinocandin resistance in Candida glabrata isolates in India despite background prevalence of strains with defects in the DNA mismatch repair pathway. Antimicrob Agents Chemother. 2018;62:e00195-18. https://doi.org/10.1128/ AAC.00195-18

42. Bordallo-Cardona MÁ, Agnelli C, Gómez-Nuñez A, Sánchez-Carrillo C, Bouza E, Muñoz P, et al. MSH2 gene point mutations are not antifungal resistance markers in Candida glabrata. Antimicrob Agents Chemother. 2018;63:e01876-18. https:/ / doi.org/10.1128/ AAC.01876-18

43. Biswas C, Marcelino VR, Van Hal S, Halliday C, Martinez E, Wang Q, et al. Whole genome sequencing of Australian Candida glabrata isolates reveals genetic diversity and novel sequence types. Front Microbiol. 2018;9:2946. https:/ / doi.org/10.3389/fmicb.2018.02946

44. Yao D, Chen J, Chen W, Li Z, Hu X. Mechanisms of azole resistance in clinical isolates of Candida glabrata from two hospitals in China. Infect Drug Resist. 2019;12:771-81. https://doi.org/10.2147/IDR.S202058

45. Whaley SG, Berkow EL, Rybak JM, Nishimoto AT, Barker KS, Rogers PD. Azole antifungal resistance in Candida albicans and emerging non-albicans Candida species. Front Microbiol. 2017;7:2173. https://doi.org/10.3389/ fmicb.2016.02173

46. Tantivitayakul P, Lapirattanakul J, Kaypetch R, Muadcheingka T. Missense mutation in CgPDR1 regulator associated with azole-resistant Candida glabrata recovered from Thai oral candidiasis patients. J Glob Antimicrob Resist. 2019;17:221-6. https://doi.org/10.1016/j.jgar.2019.01.006

47. Pais P, Galocha M, Viana R, Cavalheiro M, Pereira D, Teixeira MC. Microevolution of the pathogenic yeasts Candida albicans and Candida glabrata during antifungal therapy and host infection. Microb Cell. 2019;6:142-59. https:// doi.org/10.15698/mic2019.03.670

48. Ni Q, Wang C, Tian Y, Dong D, Jiang C, Mao E, et al. CgPDR1 gain-of-function mutations lead to azole-resistance and increased adhesion in clinical Candida glabrata strains. Mycoses. 2018;61:430-40. https:/ / doi.org/10.1111/myc.12756

49. Brunke S, Hube B. Two unlike cousins: Candida albicans and C. glabrata infection strategies. Cell Microbiol. 2013;15:701-8. https:// doi.org/10.1111/cmi.12091

50. Lortholary O, Desnos-Ollivier M, Sitbon K, Fontanet A, Bretagne S, Dromer F; French Mycosis Study Group. Recent exposure to caspofungin or fluconazole influences the epidemiology of candidemia: a prospective multicenter study involving 2,441 patients. Antimicrob Agents Chemother. 2011;55:532-8. https:// doi.org/10.1128/ AAC.01128-10

Address for correspondence: Jong Hee Shin, Department of Laboratory Medicine, Chonnam National University Medical School, 42 Jebong-ro, Dong-gu, Gwangju 61469, South Korea; email: shinjh@chonnam.ac.kr 